\title{
ВЛИЯНИЕ ДЕТСКИХ ПЕСЕН НА СОЦИАЛЬНО-ПСИХОЛОГИЧЕСКУЮ АДАПТАЦИЮ ОБУЧАЮЩИХСЯ НАЧАЛЬНЫХ КЛАССОВ РЕСПУБЛИКИ ИРАК
}

\section{THE INFLUENCE OF CHILDREN'S SONGS ON THE SOCIO-PSYCHOLOGICAL ADAPTATION OF STUDENTS IN PRIMARY CLASSES IN THE REPUBLIC OF IRAQ \\ Alawadi Maryam Neamah Joudah M. Chibisova}

Summary: The article is devoted to the description of the influence of music lessons (in particular, children's songs) on the socio-psychological adaptation of primary school students in the Republic of Iraq. The aim of this work is to analyze the influence of children's songs on the adaptive capabilities of persons with disabilities. The scientific novelty of the work is the field of application - primary schools of the Republic of Iraq. The author summarizes the activities of teachers of special education with different categories of children with disabilities and comes to the conclusion that it is necessary to include music lessons in the curriculum of secondary schools in the Republic of Iraq.

Keywords: children's songs, social and psychological adaptation, special classes of elementary school, the Republic of Iraq, special education teacher.

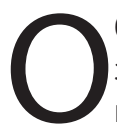
бучение детей с ограниченными возможностями здоровья (ОВ3) в условиях общеобразовательной школы является одной из актуальных проблем современного общества. Большое внимание уделяется проблемам социально-психологической адаптации, интеграции и социализации детей с ОВ3. У детей, имеющих нарушение слуха, зрения, речи, опорно-двигательного аппарата, умственную отсталость, задержку психического развития, а также комплексные нарушения психофизического развития, возникают сложности в процессе обучения, связанные с возможностью адекватного реагирования и возникновением трудностей в достижении поставленных целей [1, с. 19].

Ребенок с особыми образовательными потребностями нуждается в профессиональной помощи учителя специального образования, деятельность которого направлена на оказание помощи в интеграции и социальной адаптации лицам с ОВ3 [3, с. 14].

Целью данной работы является анализ влияния детских песен на адаптационные возможности лиц с ОВ3. Научной новизной работы является область примене-

\author{
Альавади Марьям Неамах Джудах \\ Аспирант, Московский педагогический государственный \\ университет, Москва \\ Mrmr.Mrmr.Mrmr.Mrmr@mail.ru \\ Чибисова Марина Юрьевна \\ К.nсх.н., дочент, Московский педагогический \\ государственный университет, Москва \\ marina_jurievna@mail.ru
}

Аннотация: Статья посвящена описанию влияния музыкальных занятий (В частности детских песен) на социально-психологическую адаптацию учеников начальных классов Республики Ирак. Целью данной работы является анализ влияния детских песен на адаптационные возможности лиц с ОВЗ. Научной новизной работы является область применения - начальные школы Республики Ирак. Автор обобщает деятельность учителей специального образования с разными категориями детей с ОВЗ и приходит к выводу о необходимости включения музыкальных занятий в программу общеобразовательных школ Республики Ирак.

Ключевые слова: детские песни, социально-психологическая адаптация, специальные классы начальной школы, Республика Ирак, учитель специального образования. ния - начальные школы Республики Ирак.

Практическая ченность данной статьи заключается в том, что результаты данной работы могут быть интересны педагогам дополнительного образования, учителям специального образования, учителям начальных классов, а также родителям детей, имеющих ОВ3.

Социально-психологической адаптации детей с ОВ3 посвящены статьи современных исследователей А.Э. Симановского и С.Н. Воронина (2014), И.В. Андрусевой и В.Э. Болдырева (2020), авторов коллективной монографии О.А. Апуневич, И.А. Букиной, И.Н. Берниковой, посвященные инклюзивному образованию детей с ОВ3, их психолого-педагогической и социальной реабилитации и адаптации. Необходимо отметить работы М.Н.Д. Альавади (2021), М.Н.Д. Альавади и М.Ю. Чибисовой (2021), в которых интеграция детей с ОВ3 в Республике Ирак.

В государственных школах Республики Ирак существуют специальные классы, в которых обучаются дети с ОВ3 с первого по четвертый класс. К ним относятся «Школа мученика Наима», «Школа Аль-Атмар», «Школа 
Таблица 1.

Деятельность учителя специального образования для достижения социально-психологической адаптации детей с ОВ3

\begin{tabular}{|c|c|c|}
\hline Категория детей с ОВЗ & $\begin{array}{l}\text { Влияние детских песен на социально-психологиче- } \\
\text { скую адаптацию }\end{array}$ & $\begin{array}{c}\text { Деятельность учителя специального образования, } \\
\text { направленная на достижение социально-психологи- } \\
\text { ческой адаптации }\end{array}$ \\
\hline $\begin{array}{l}\text { Дети с нарушениями слуха } \\
\text { (слабослышащие, } \\
\text { позднооглохшие) }\end{array}$ & $\begin{array}{l}\text { 1. Развитие моторной и двигательной сфер у слабос- } \\
\text { лышащих детей. } \\
\text { 2. Упорядочение хаотичных движений. } \\
\text { 3. Облегчает преодоление барьеров при вхождении } \\
\text { в социум. }\end{array}$ & $\begin{array}{l}\text { Мониторинг развития речи, мышления, зри- } \\
\text { тельного и тактильно-двигательного восприятия } \\
\text { с использованием методик Э.И. Леонгарда, Е.Г. } \\
\text { Самсоновой, Е.А. Стребелевой, И.В. Королевой, 0.В. } \\
\text { Зонтовой в форме тестов, корректурных проб, бесед } \\
\text { и диагностических игр. }\end{array}$ \\
\hline $\begin{array}{l}\text { Дети с нарушениями зрения (слабовидя- } \\
\text { щие) }\end{array}$ & $\begin{array}{l}\text { 1. Достижение состояния уверенности в себе, ощу- } \\
\text { щения собственного эмоционального благополучия } \\
\text { и своей значимости в коллективе. } \\
\text { 2. Умение владеть своим телом, согласовывать свои } \\
\text { движения с музыкой. } \\
\text { 3. Умение согласовывать свои движения с действи- } \\
\text { ями других детей. }\end{array}$ & $\begin{array}{l}\text { 1. Изучение образовательных потребностей слабо- } \\
\text { видящих детей. } \\
\text { 2. Выявление адаптивных возможностей учеников } \\
\text { и уровня социализации. } \\
\text { 3. Изучение потребностей слабовидящих детей с } \\
\text { интеллектуальной недостаточностью и развитие } \\
\text { сенсорных, моторных и психических функций. }\end{array}$ \\
\hline Дети с нарушениями речи (логопаты) & $\begin{array}{l}\text { 1. Помогает воспитывать уверенность в себе, вы- } \\
\text { держку и волевые черты характера. } \\
\text { 2. Достижение ситуации успеха, самореализации, } \\
\text { гармоничного развития. } \\
\text { 3. Помогает в развитии координации движения, } \\
\text { формирует двигательные навыки. } \\
\text { 4. Способствует развитию ловкости, силы и вы- } \\
\text { носливости. }\end{array}$ & $\begin{array}{l}\text { Особое внимание необходимо уделять специфиче- } \\
\text { скому развитию познавательных интересов. При } \\
\text { этом следует учитывать отставание в познаватель- } \\
\text { ной активности, которое порождается влиянием } \\
\text { речевого дефекта, сужению социальных контактов, } \\
\text { неправильными приемами семейного воспитания. } \\
\text { Задачи: } \\
\text { 1. Создание доброжелательной обстановки. } \\
\text { 2. Укрепление у ребенка веры в себя и свои силы. } \\
\text { 3. Формирование интереса к учебе и снятию отрица- } \\
\text { тельных переживаний. }\end{array}$ \\
\hline $\begin{array}{l}\text { Дети с нарушениями } \\
\text { опорно-двигательного аппарата }\end{array}$ & $\begin{array}{l}\text { 1. Способствует гармоничному развитию личности } \\
\text { ребенка. } \\
\text { 2. Способствует формированию и развитию внима- } \\
\text { ния и памяти. } \\
\text { 3. Использование средств ИКТ развивает наглядно- } \\
\text { действенное и наглядно-образное мышление. } \\
\text { 4. Ритмика способствует формированию ловкости и } \\
\text { выносливости. }\end{array}$ & $\begin{array}{l}\text { 1. Способствовать снижению эмоционального дис- } \\
\text { комфорта у детей. } \\
\text { 2. Способствовать повышению активности и само- } \\
\text { стоятельности детей. } \\
\text { 3. Коррекция самооценки и уровня самосознания. } \\
\text { 4. Использование тактических и технических при- } \\
\text { емов психологической коррекции, направленных } \\
\text { на устранение имеющегося дефекта с учетом } \\
\text { индивидуально-психологических факторов. }\end{array}$ \\
\hline Дети с умственной отсталостью & $\begin{array}{l}\text { Способствует познанию окружающего мира, по- } \\
\text { стижению сложных законов человеческого бытия, } \\
\text { расширению кругозора, умственному развитию и } \\
\text { воспитанию ребенка. } \\
\text { В процессе музыкальных занятий развиваются и } \\
\text { корригируются сенсорные, моторные, речевые и } \\
\text { мыслительные способности. }\end{array}$ & $\begin{array}{l}\text { 1. Работа по развитию зрительного, слухового, } \\
\text { тактильного и обонятельного восприятия. } \\
\text { 2. Оценка индивидуальных способностей ребенка. } \\
\text { 3. Одобрение или стимуляция дальнейших } \\
\text { действий, использование подсказок и наводящих } \\
\text { вопросов. } \\
\text { 4. Определение уровня актуального развития в } \\
\text { соответствии с возрастной нормой. }\end{array}$ \\
\hline Дети с задержкой психического развития & $\begin{array}{l}\text { 1. Развитие навыков коммуникации. } \\
\text { 2. Способствует развитию координации движений и } \\
\text { мелкой моторики. } \\
\text { 3. Способствует развитию чувства ритма. } \\
\text { 4. Направлено на развитие слухового внимания. }\end{array}$ & $\begin{array}{l}\text { 1. Оценка познавательных способностей и социаль- } \\
\text { ных возможностей. } \\
\text { 2. Способствует повышению познавательной актив- } \\
\text { ности детей. } \\
\text { 3. Способствует формированию психологической } \\
\text { основы для полноценного развития личности. }\end{array}$ \\
\hline
\end{tabular}


Аль-Мундхир», «Школа Саид Аль-Шухада» и «Школа АльТалиа» [2, с. 8]. Как отмечает Джасим Рана Абдальссатар Джассим, детям с различными нарушениями нравственного, физического и психического здоровья для достижения социальной адаптации требуется системная организация двигательной активности для развития сохранных анализаторов [5, с. 4523].

В школах Республики Ирак для детей с ОВ3 проводятся музыкальные занятия, которые способствуют формированию речевой функции и интонационной стороны устной речи у детей с нарушением слуха, а также развитию голосового аппарата у детей с нарушением речи, 3ПР и умственной отсталостью [4, с. 22].

Рассмотрим влияние музыкальных композиций на адаптацию детей с различными категориями детей с ОВ3 и работу учителя специального образования для достижения успешной социально-психологической адаптации в табл. 1.
На основании теоретических данных нами был проведено социологическое исследование, посвященное анализу влияния детских песен на социально-психологическую адаптацию детей с ОВ3. Объектом исследования является музыкальное занятие, проведенное для детей с ОВ3. Предмет исследования - социально-психологическая адаптация детей. Целью исследования является изучение влияния детских песен на адаптацию детей с ОВ3 в социальной группе. Метод исследования - наблюдение. В социологическом исследовании принимали участие 40 детей с ОВ3. Продолжительность исследования 1 месяц. В течение месяца дети с ОВ3 2 раза в неделю занимались с музыкальным руководителем и учителем специального образования. В таблице 2. представлена общая характеристика валидной выборки.

В ходе социологического исследования нами были выявлены положительное влияние детских песен на детей с ОВ3 (диаграмма 1).

Таблица 2.

Участники социологического эксперимента

\begin{tabular}{|l|c|}
\multicolumn{1}{|c|}{ Категория детей с ОВ3 } & Количество детей с ОВЗ \\
\hline Дети с нарушениями слуха (слабослышащие, позднооглохшие) & 8 \\
\hline Дети с нарушениями зрения (слабовидящие) & 7 \\
\hline Дети с нарушениями речи (логопаты) & 6 \\
\hline Дети с нарушениями опорно-двигательного аппарата & 6 \\
\hline Дети с умственной отсталостью & 8 \\
\hline Дети с задержкой психического развития & 5 \\
\hline
\end{tabular}

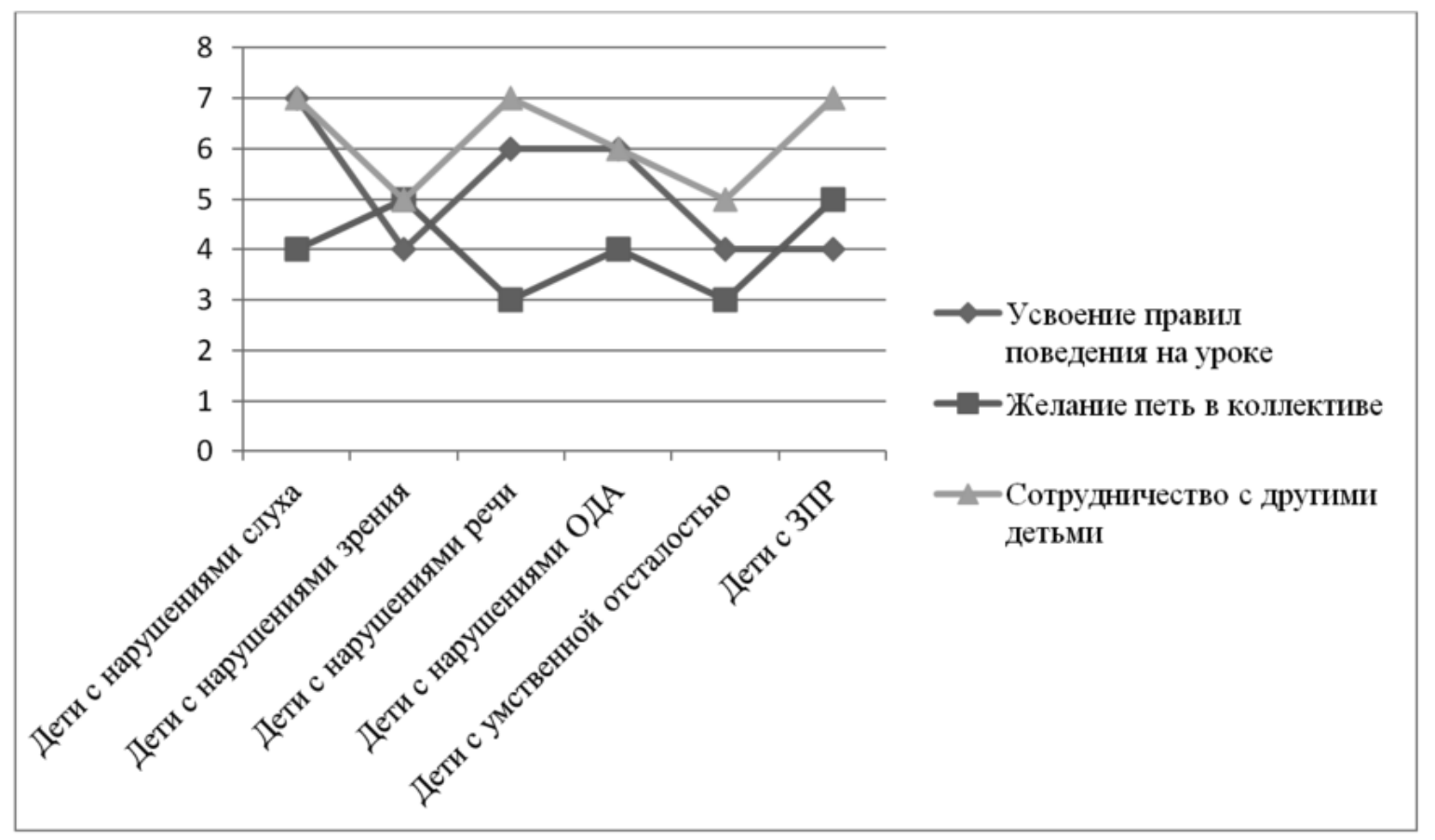

Диаграмма 1. 
Нами было выделено три главных показателя социально-психологической адаптации: 1) усвоение норм и правил в обществе (поведение на уроке); 2) желание сотрудничать со сверстниками; 3) желание петь в коллективе - осуществлять общее дело с другими детьми. Высокие показатели этих трех компонентов будут свидетельствовать об успешном влиянии детских песен на социально-психологическую адаптацию детей с ОВ3.

В ходе социологического наблюдения и исследования поведения детей на музыкальных занятиях мы пришли к следующим результатам:

1. На музыкальных занятиях с использованием детских песен 92,5\% детей активно сотрудничали с другими детьми, объединялись в пары, общались после занятий, отвечали на вопросы музыкального руководителя и принимали участие в беседе.

2. Показатель «желание петь в коллективе» является значимым, поскольку дети с ОВ3 испытывают трудности, связанные с вступлением в коммуникативный контакт, ощущением непредсказуемости со стороны партнера-коммуниканта. Однако детские песни на музыкальных занятиях положительно повлияли на желание детей петь в коллективе - $60 \%$ детей с ОВ3 успешно пели вместе с учителем музыки.

3. Отметим, то $92,5 \%$ детей с ОВ3 успешно освоили правила поведения на уроке, поднимали руку, когда хотели ответить на вопрос учителя.

Проанализировав влияние музыкальных занятий, и, в частности, детских песен, на развитие социально-психологической адаптации детей с ОВ3 мы пришли к следующим выводам:

1. Изучение детских песен на музыкальных занятиях в Республике Ирак с детьми, имеющими ОВ3, способствует развитию интеллектуальных, речевых, моторно-двигательных и иных навыков, способствующих развитию кругозора, умственному развитию и уверенности в себе, что, в свою очередь, помогает успешной социальной адаптации в детском коллективе. В ходе социологического наблюдения мы отметили, что дети с ОВЗ при изучении детских песен способны активно усваивать правила поведения на уроке (92,5\%), охотно вступают в контакт со сверстниками (92,5\%), а также принимают участие в коллективном пении (60\%). Эти показатели свидетельствуют о положительном влиянии детских песен на социально-психологическую адаптацию детей с ОВ3.

2. В Республике Ирак созданы условия для работы с детьми, имеющими ОВ3: в школах работают психологи, учителя специального образования, деятельность которых направлена на снижение эмоционального дискомфорта у детей, а также повышению уровня социальной адаптации.

3. Изучение детских песен в классах начальной школы облегчают преодоление социальных барьеров у детей с разной категорией ОВЗ. Это свидетельствует о необходимости включения музыкальных занятий в программу общеобразовательных школ Республики Ирак.

\section{ЛИТЕРАТУРА}

1. Владельщикова Д.Н. Проблема социально-психологической адаптации детей-инвалидов / Д.Н. Владельщикова, О.А Обухова // Вестник совета молодых ученых и специалистов Челябинской области. - 2016. - № 1 (12). -С. 19-22.

2. Деманова, С.В. Образование в Республике Ирак: правовые и социальные аспекты / С.В. Деманова // Тенденции развития науки и образования. - 2017. № 29 (1). - C. 8-13.

3. Комплексная коррекционно-реабилитационная работа с детьми в условиях инклюзивной образовательной среды: монография / И.А. Кувшинова, Е.А. Овсянникова, В.А. Чернобровкин [и др.]. - Магнитогорск: Изд-во Магнитогорск. гос. техн. ун-та им. Г.И. Носова, 2020. - 141 с.

4. Музыкальное воспитание детей с проблемами в развитии и коррекционная ритмика / Е.А. Медведева, Л.Н. Комиссарова, Г.Р. Шашкина, 0.Л. Сергеева; под ред. Е.А. Медведевой. - М.: Издательский центр «Академия», 2002. - 224 с.

5. Фадель, Саад Аббас. Особенности здоровьесбережения в образовательном пространстве Республики Ирак / Саад Аббас Фадель // Фундаментальные исследования. - 2015. - № 2 (Ч. 20). - С. 4522-4527.

( Альавади Марьям Неамах Джудах (Mrmr.Mrmr.Mrmr.Mrmr@mail.ru), Чибисова Марина Юрьевна (marina_jurievna@mail.ru). 